\title{
A technique for EEG recording in the awake parakeet
}

\author{
ROBERT J. DOOLING and JAMES K. WALSH \\ Saint Louis University, St. Louis, Missouri 63103
}

This manuscript describes a technique for EEG recording in the awake parakeet.

Electrophysiological research with small animals often requires: (1) the proper stereotaxic instrument for the species, (2) some degree of surgical sophistication, (3) sterile surgical conditions, (4) an accurate atlas of the species' brain and cranial bones, and (5) an anesthetic during the recording session. One of the standard techniques used to circumvent some of these problems is to use stainless steel screw electrodes that are screwed into the skull and held by dental acrylic. However, the parakeet skull is extremely thin and fragile-as is the case with most small birds. This precluded the use of screw electrodes and prompted the development of alternative and somewhat simpler methods for attaching electrodes to the parakeet. These procedures may be of particular value in view of the recent interest in avian slecp processes and sensory processes (Van Twyver \& Allison, 1972; Dooling \& Saunders, 1974).

The skin covering the underside of the lower beak in the parakeet is thin. This enables one to insert a 30 -ga, Kynar-coated solid wire through the underside of the mandible into the oral cavity and wrap it tightly around the lateral portion of the lower beak. (See lower half of Figure 1.) The length of wire wrapped around the beak is stripped to permit good electrical contact. This procedure is applied to both sides of the parakeet's beak to provide both a ground and a reference electrode. The insulated portions of these beak electrode wires are led to the back of the bird's head, pulled taut, and threaded through the side holes of a standard three-pole transist or plug as indicated in the upper half of Figure 1.

A number of types of skull electrodes have been used in combination with these beak electrodes. These include a $2 \mathrm{~mm}$ in diam coil of silver wire or a disk of silver foil, dental screws, and inverted wire nails. Regardless of the electrode type, it is attached to the skull using the following general procedures.

The bird's head is cleaned with alcohol, and an incision is made along the medial axis of the scalp extending from the cere about $2 \mathrm{~cm}$ posteriorly. The skin is pulled back, the skull surface wiped clean with a cotton swab, and the electrode cemented to the skull with conventional dental acrylic. The electrode lead is then led to the third pole of the transistor plug. The

Requests for reprints should be sent to R. J. Dooling, Department of Psychology, St. Louis University, St. Louis, Missouri 63103. entire process, using any type of scalp electrode can be accomplished in about $20 \mathrm{~min}$ with a light dose of Nembutal $(.15 \mathrm{mg} / \mathrm{kg})$ administered intraperitoneally. Resistance between scalp and mandible electrodes is typically 10,000 to $20,000 \mathrm{ohms}$.

During the recording session, a male connector is inserted in the plug. With the parakeet sitting quietly in a dark chamber, we have observed the EEG for periods up to $4 \mathrm{~h}$. A sample EEG record is shown in the upper portion of Figure 2. An averaged auditory evoked response obtained with this electrode assembly is shown in the lower half of the figure.

The advantages obtained with this technique include the following: (1) construction of the electrode assembly is relatively simple and inexpensive; (2) there appears to be a minimal interference with eating,
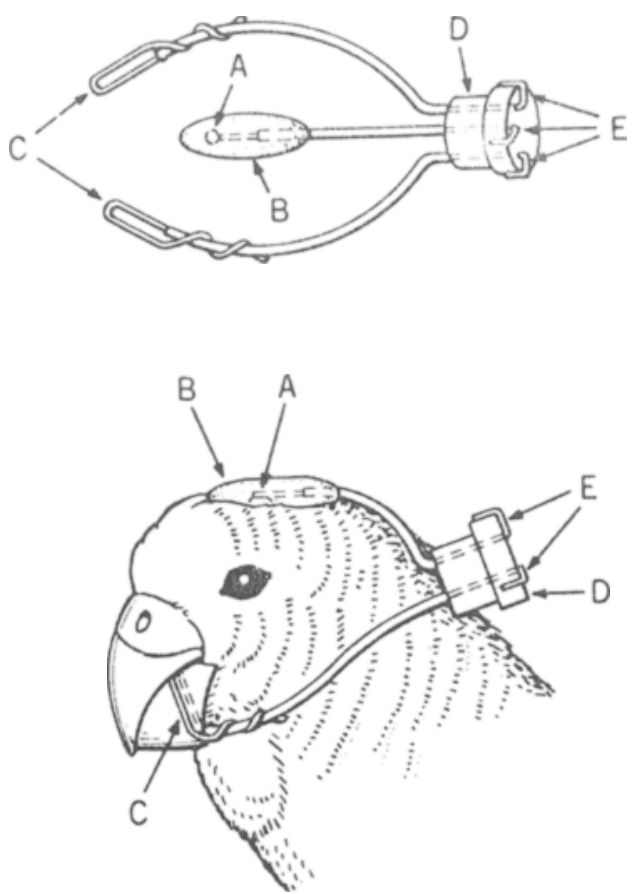

Figure 1. Top: Superior view of the electrode assembly. Letters indicate the following; (a) silver disk electrode, (b) dental acrylic, (c) wires serving as ground and reference electrodes, (d) three-pole transistor plug, and (e) electrode wires in place in transistor plug.

Bottom: Lateral view of the assembly in place on the bird's head. 


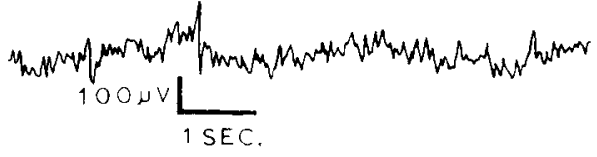

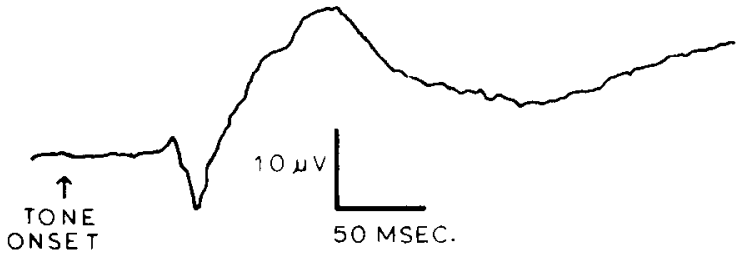

Figure 2. Top: Tracing of parakeet EEG recorded using the described technique. This tracing is similar to those reported by Van Twyver and Allison (1972) for the pigeon using cortical electrodes.

Bottom: Typical averaged auditory evoked response to 50 -msec tone bursts of $1000 \mathrm{~Hz}$ using this technique. This evoked response is an average of 750 presentations of a tone burst at a sound pressure level of $85 \mathrm{~dB}\left(\right.$ re $20 \mu \mathrm{N} / \mathrm{m}^{2}$ ).

sleeping, and other normal activities; (3) the assembly is sufficiently stable to allow repeated testing; (4) the attachment procedure is surgically simple with minimal exposure of the animal to anesthesia, and infection is not a problem, and; (5) successful EEG recordings can be obtained from unanesthesized animals without cranial cavity invasion or the use of a restraining device.
Possible shortcomings include the following: (1) the dental acrylic does not normaly hold fast to the skull for more than 3-4 weeks; (2) the size of a small bird's head limits the number of electrodes that can be cemented to the animal's skull at any one time, and; (3) since the wires wrapped around the beak must be thin enough to avoid interference with eating, frequent flexing because of head and neck movement often causes breakage. Since the beak electrodes can be replaced in a matter of minutes without anesthesia, this is not a severe drawback.

Finally, there are alternatives to beak electrodes. The area of the skull just behind the cere is somewhat thicker, and it is possible to drill holes just deep enough on either side of midline to hold stainless steel straight pins in a vertical position while applying the dental acrylic. These straight pins can serve as ground and reference electrodes. This procedure, however, requires a considerable amount of practice with a dental drill to avoid accidental invasion of the cranial cavity.

\section{REFERENCES}

Dooling. R., \& Saunders, J. Hearing in the parakeet. (Melopsittacus undulatus): Absolute thresholds, critical ratios frequency difference limens, and vocalizations. Journal of Comparative and Physiological Psychology, in press, 1974.

Van Twyver, H., \& Allison, T. A. polygraphic and behavioral study of sleep in the pigeon. Experimental Neurology, 1972 35, 138-153.

(Received for publication July 30, 1974, revision accepted September 24, 1974.) 